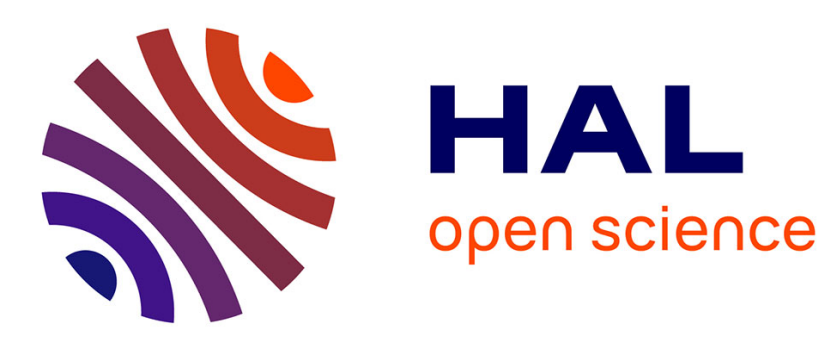

\title{
Mechanoregulation of PDZ Proteins, An Emerging Function
}

Elsa Bazellières, André Le Bivic

\section{To cite this version:}

Elsa Bazellières, André Le Bivic. Mechanoregulation of PDZ Proteins, An Emerging Function. Mechanoregulation of PDZ Proteins, An Emerging Function, pp.257 - 275, 2021, 10.1007/978-10716-1166-1_15. hal-03557734

\section{HAL Id: hal-03557734 \\ https://hal.science/hal-03557734}

Submitted on 4 Feb 2022

HAL is a multi-disciplinary open access archive for the deposit and dissemination of scientific research documents, whether they are published or not. The documents may come from teaching and research institutions in France or abroad, or from public or private research centers.
L'archive ouverte pluridisciplinaire HAL, est destinée au dépôt et à la diffusion de documents scientifiques de niveau recherche, publiés ou non, émanant des établissements d'enseignement et de recherche français ou étrangers, des laboratoires publics ou privés. 


\title{
Chapter 15
}

\section{Mechanoregulation of PDZ Proteins, An Emerging Function}

\section{Elsa Bazellières and André Le Bivic}

\begin{abstract}
Mechanical forces have emerged as essential regulators of cell organization, proliferation, migration, and 5 polarity to regulate cellular and tissue homeostasis. Changes in forces or loss of the cellular response to them 6 can result in abnormal embryonic development and diseases. Over the past two decades, many efforts have 7 been put in deciphering the molecular mechanisms that convert forces into biochemical signals, allowing 8 for the identification of many mechanotransducer proteins. Here we discuss how PDZ proteins are 9 emerging as new mechanotransducer proteins by altering their conformations or localizations upon force 10 loads, leading to the formation of macromolecular modules tethering the cell membrane to the actin 11 cytoskeleton.

Key words PDZ proteins, Forces, Tight junctions, Adherens junctions, Actomyosin

1 A Brief Introduction on Mechanotransduction/Mechanoregulation in Biology

All the cells and tissues of the body are subject to external and 15 internal forces. These forces can affect the shape and intracellular 16 organization of cells, their proliferation, their migration, and their 17 intercellular interactions. Forces influence the development of 18 embryos [1] as well as cell functions and homeostasis in the adult 19 [2]. Moreover, many disease states are characterized by changes in 20 these forces and/or a loss of the normal cellular response to them 21 [3]. Over the last decade, mechanotransduction has emerged as a 22 key process in development and diseases. Mechanotransduction can 23 be defined as a cellular event that converts a mechanical input such 24 as fluid shear stress (blood vessels), stretch (lung, intestine), 25 osmotic forces (urinary tract), mechanical load (bone, muscle) 26 $[4,5]$ as well as the impact of the stiffness of the extracellular matrix 27 (ECM) that surrounds most cells leading to a biochemical response 28 [6]. In well-studied examples of mechanotransduction, proteins 29 can undergo force-induced changes into conformations that lead 30 to modification in affinity for binding partners or catalytic activity. 31 The mechanical load triggers biochemical changes that can 32 
propagate via the activation of specific signaling pathways [7]. In a simple context, the mechanical load can accelerate the association or dissociation of protein-ligand bonds [8]. In the case of adhesion proteins, that exhibit catch-bond behavior, mechanical loads can produce changes in the conformation of the proteins that lead to high affinity for a binding partner [9-11].

Deciphering how fundamental physical principles are controlled by protein interactions is central to understand how forces are converted into biochemical signals. Elucidation of the specificity, selectivity, and regulatory mechanisms involved in protein-protein interactions can therefore provide important insights into many biological processes such as cell proliferation, cell migration, and cell polarity. Structural studies have revealed that mechanosensitive proteins with multiple domains and flexible interdomain interfaces can pass through multiple conformations [12, 13]. For example, a bent conformation can open up to a straighter arrangement of domains along the direction of the applied force. These changes in conformation result in modification of the affinity for the binding partners, exposure or hiding of different catalytic domains that will trigger differential intracellular signaling responses or even redistribution of the protein within the cell [14-16]. Among the proteins that mediate protein-protein interactions, there is the large PDZ (postsynaptic density 95/Disc large/Zonula occludens) family. Most of the PDZ proteins are multimodular scaffold proteins and often contain multiple PDZ domains which can interact with various binding partners and thereby assemble supramolecular signaling complexes [17].

As PDZ domains interact with motifs present in many proteins, understanding the regulatory mechanism of PDZ mediated interactions is important to gain insight into biological processes. So far, posttranslational modifications, autoinhibition, and allosteric interactions have been proposed to regulate PDZ-mediated interactions and thus intracellular signaling [18], but little is known about the impact of mechanical inputs on PDZ proteins. In this review, we will focus on the current knowledge on the mechanoregulation of PDZ proteins, focusing on few recent findings.

Biological mechanotransducers can be defined as a single protein or response to mechanical stimuli. These mechanotransducers can participate in mechanoreception and mechanotransmission as direct mechanosensitive structure, which respond by altering their conformation upon force loads, or as second line mechanotransducers. Among the mechanotransducer proteins studied so far, the PDZ protein family is emerging as a new pool of protein sensitive to 
forces, but only few examples are known so far. In epithelial cells, 78 the adhesion machineries at the cell-cell or cell-substrate interfaces 79 are known to play an important role in mechanotransduction 80 $[10,19]$. These machineries are composed of several proteins, 81 and many of them are part of the PDZ family [20]. Being 82 integrated in a complex modular array tethering the cell membrane 83 to the cell cytoskeleton, the adhesion scaffolding PDZ proteins 84 might constitute an important link to transduce the mechanical 85 signals into an appropriate cell response to maintain cellular 86 homeostasis. We will thus focus on PDZ proteins from the adhe- 87 sion machinery that have been recently shown to be regulated by 88 forces in a direct or indirect manner (Fig. 1).

\section{Force Regulated PDZ Proteins}

$\mathrm{ZOl}$ is a tight junction scaffolding protein that belongs to the 91 MAGUK (membrane associated guanylated kinase homolog) fam- 92 ily. It is characterized by the occurrence of three PDZ, one $\mathrm{SH} 3$ and 93 a GUK (guanylate kinase homologous domain) domains 94 [21]. ZOl is a cytoplasmic protein, that anchors actin filaments 95 through its actin binding domain at its $\mathrm{C}$ terminal region 96 $[22,23]$. At the $\mathrm{N}$-terminus, the PDZ1 and PDZ3 domains bind 97 to the tight junction membrane associated proteins, Claudins and 98 JAM-A, and to TAZ, a member of Hippo pathway, while the PDZ2 99 domain promotes heterodimerization between $\mathrm{ZOl}$ and either 100 ZO2 or ZO3 [22, 24-26]. A larger region encompassing the 101 PDZ3, SH3, U5, and GUK domains (ZPSG-1) interacts with and 102 recruits to junctions the transmembrane TJ protein occludin, but 103 also DbpA/ZONAB (DNA binding protein A/ZOl associated 104 Nucleic Acid-binding protein) [27, 28]. The sequestration of 105 DbpA by ZO1 and ZO2 at the junctions of confluent monolayers 106 inhibits its nuclear activity that regulates gene expression and cell 107 proliferation [27-30].

Recently, Spadaro et al. demonstrated that ZOl stretches upon 109 mechanical forces [31]. In 2011, Then et al. have already proposed 110 an impact of membrane tension on the localization of $\mathrm{ZOl} 111$ [32]. Under hyperosmotic stress that generates an increase in 112 membrane tension, the actin cytoskeleton is reorganized with the 113 appearance of a dense F-actin cortical ring. In this condition, ZOI 114 expression is increased, and it colocalizes with the newly formed 115 actin ring [32]. As ZOl is anchored to the actin filaments through 116 - -terminal region, this change in actin organization exerts direct 117 -....ing forces on the $\mathrm{ZOl}$ protein. When present as a heterodimer 118 with ZO2 within cells, ZO1 is in a stretched configuration that 119 allows binding to DpbA. However, the depletion of ZO2 together 120 with an inhibition of myosin contractility promotes a folding of the 121 $\mathrm{N}$-terminal and C-terminal end of ZO-1, and releases the 122 
A. Tight Junctions
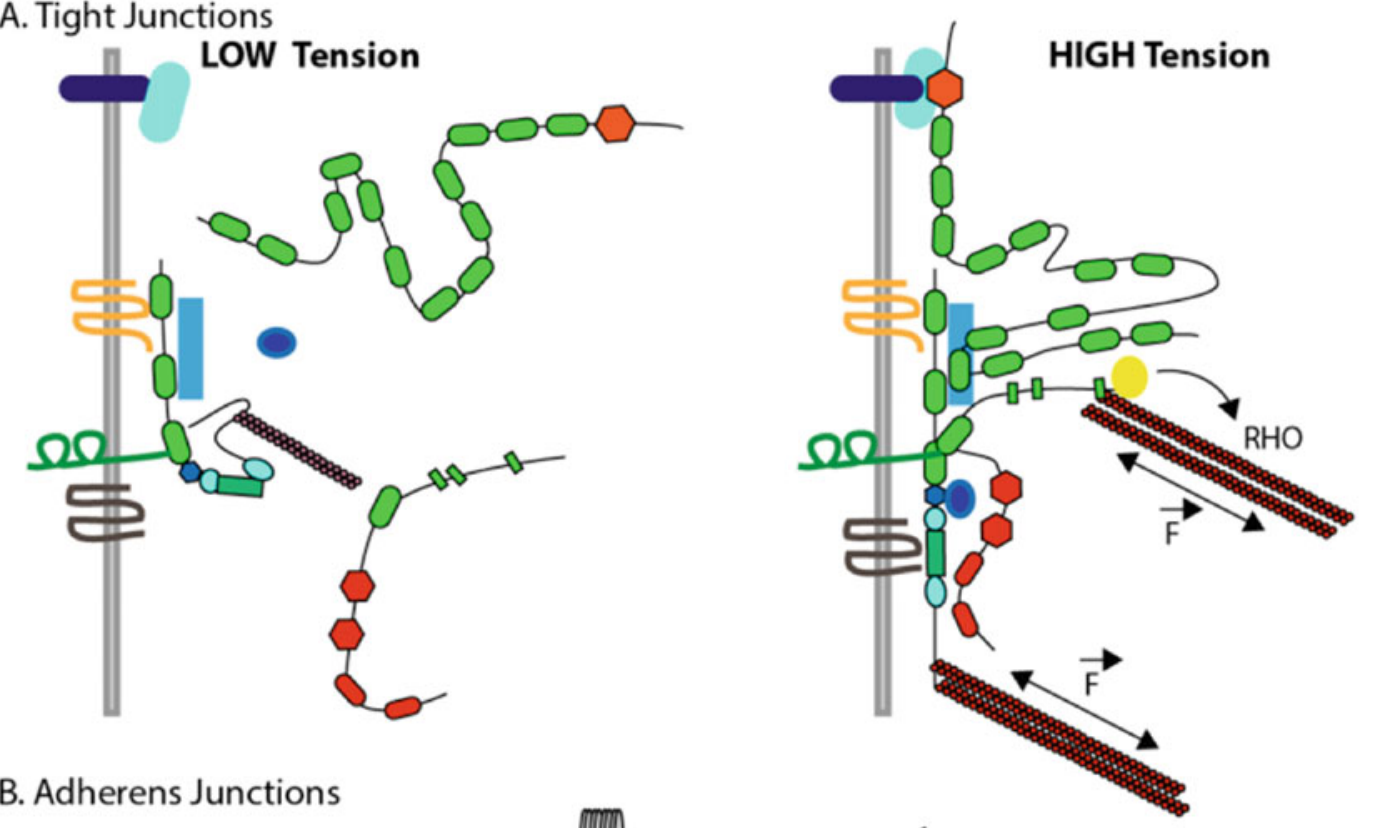

B. Adherens Junctions
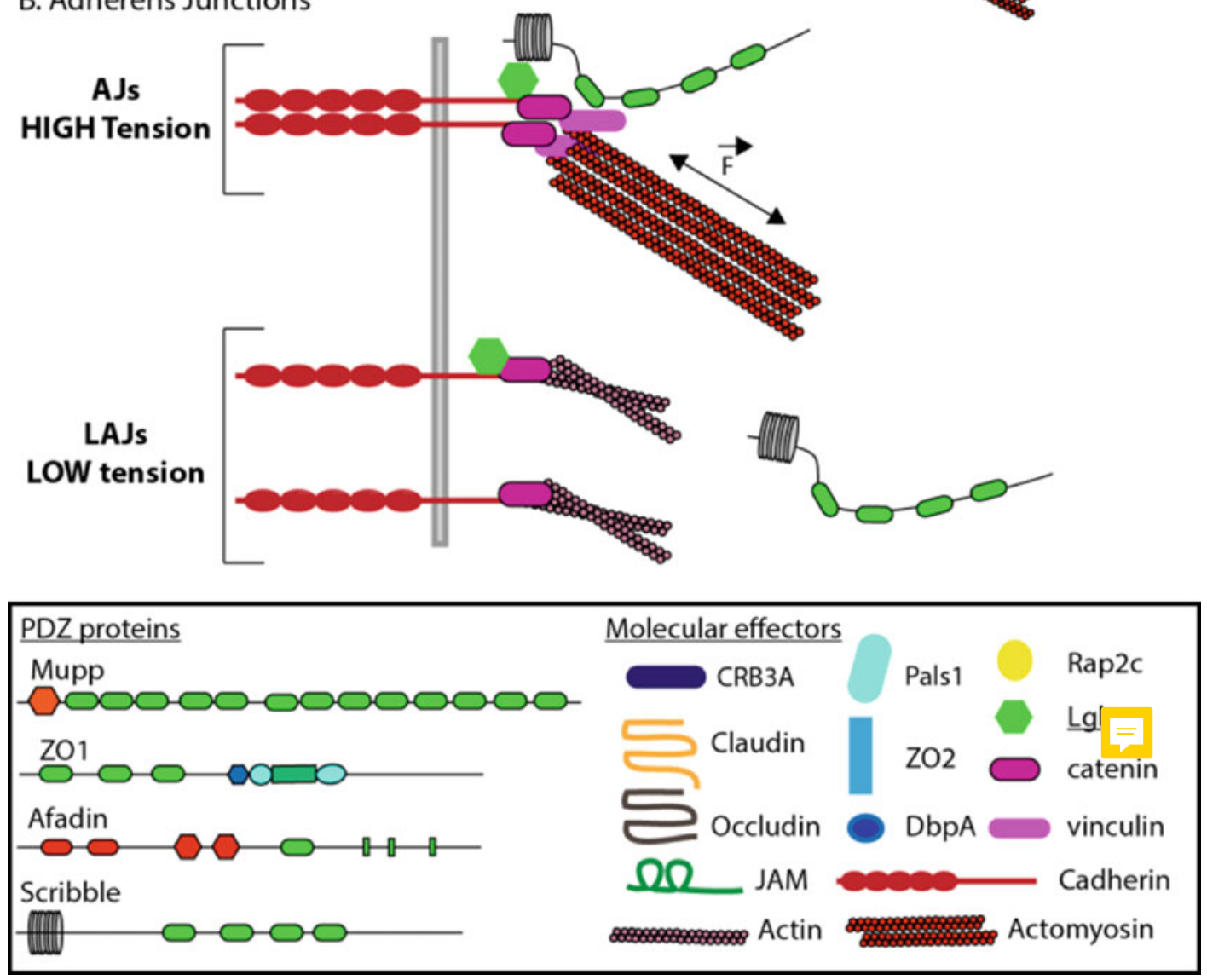

Fig. 1 Hypothetical role of the PDZ protein in the strengthening and stabilization of intercellular adhesions. (a) At the level of the tight junctions (TJs), under low tension the mechanotransducer Z01 is in an inactive 
interaction with DpbA and Occludin. By applying linearly increas- 123 ing forces to purified full-length single ZOI molecules with mag- 124 netic tweezers, Spadaro et al. could demonstrate that both the 125 C-terminal region and the ZPSG-1 module of ZOl that comprises 126 the PDZ3, SH3, U5, and GUK domains unfold at forces ranging 127 from 5 to $20 \mathrm{pN}$, releasing the autoinhibition interaction between 128 ZPSG and C terminal domain of ZOl [31]. ZPSG-1 domain is not 129 only important for the junctional localization of ZOl but also for 130 its interaction with Occludin, DbpA, and thus for barrier formation 131 and epithelial polarization [33-38]. Forces act as an allosteric effec- 132 tor by stretching ZOl protein to promote the interaction of ZPSG- 133 1 with its ligands, occludin and DbpA. While the stretched confor- 134 mation of ZOI is the active conformation, the folded conformation 135 is the inactive form in which the ZPSG domain is autoinhibited. In 136 its inactive form, junctional $\mathrm{ZOl}$ remains anchored to the mem- 137 brane through binding of its N-terminal domain with interactors 138 such as TAZ or Claudins, while the C-terminal half is intramolecu- 139 larly autoinhibited. The release of ZPSG-1 domains may also regu- 140 late the interaction of other proteins such as $\alpha$-Catenin, Afadin, 141 JAM-A, Vinculin and Shroom2 [39].

MUPPI belongs to the family of multi-PDZ proteins and contains 144 a L27 domain at its N-terminal region followed by 13 PDZ 145 domains [40]. MUPPl is a structural paralog of PATJ, and both 146 share several binding partners such as PALS1, PAR-6, AMOT, 147 Jeap, ZO3, Claudins, or Nectins [41]. Lanaspa et al. by the use of 148 osmolarity changes demonstrated that both acute and chronic 149 hyperosmolarity in inner medullary collecting duct 3 cells induce 150 an increase in the expression of MUPP1, ZOl, and Afadin [42]. As 151 MUPPI expression increases, it localizes to the apical side of the 152 membrane at the level of the Tight Junctions (TJs). To survive 153 hyperosmotic stresses and to maintain the integrity of the cell 154 sheet with efficient barrier functions, cells have to adapt through 155

Fig. 1 (continued) conformation, and the second line mechanotransducers Afadin and Mupp1 are in the cytoplasm. The actin filaments are exerting low mechanical loads. Under high tension, generated by actomyosin bundles, ZO1 unfolds and unmasks several domains that leads to the binding with 0ccludin and JAM together with the recruitment of DbpA and Afadin. Afadin is then able to recruit Rap2c generating a positive feedback loop on RHO allowing for actin contractions and thus force generation. This increase in forces results in the recruitment of Mupp1 at the TJs, that will bind to Z01, Z02, and JAM but also potentially to the CRB3A/Pals1 polarity complex. The formation of this macromolecular complex that tethers transmembrane proteins (Claudins, Occludins, JAM) to the actin cytoskeleton is key for the strengthening and the stabilization of the TJs. (b) In the lateral domain of the cells, at the level of the lateral Adherens Junctions (LAJS), the actin filaments that binds to the E-cadherin-catenin complex, exert low tension and Scribl Ie the cytoplasm. Above the lateral junctions, the E-cadherin-catenin complex is link to vinculin and binus to actomyosin bundles that are under high mechanical loads. SCRIBBLE is also enriched at the AJ level, and plays a key role in the stabilization of the AJs 
reorganization of the actin cytoskeleton as mentioned previously 156 but also through differential expression of proteins, that move to the junctions to counterbalance the changes in membrane tension. Depletion of MUPP1, results in a disruption of the TJ barrier, with a drop of transepithelial resistance of about 25\% [42]. Molecularly, depletion of MUPPl, in hyperosmotic conditions, triggers a decreased expression and loss of membrane localization of Claudin4, a TJ protein [42]. These data clearly show that MUPPI is important in the maintenance of the epithelial homeostasis and confirm previous study that pointed out a predominant role of MUPPI in the disruption of both TJs barrier and apicobasal polarity [43-45]. A more recent study shows that MUPPI stability and degradation in endothelial cells depends on the regulation of PDZRN3, an E3 ubiquitin ligase PDZ domain containing ring finger 3 protein [46]. The interactions between PDZRN3, MUPP1, PAR3, and aPKC regulate the stabilization of TJs in endothelial cells. Perturbation of PDZRN3 expression induces degradation of MUPPl that correlates with destabilization of the actin cytoskeleton and disruption of the TJs. All these studies point toward a role of MUPPI in the stabilization and maintenance of actin cytoskeleton and TJs in cells.

20 years ago, it was suggested that MUPPl could change its conformation through the interaction of its PDZ10 domain with the 5-hydroxytryptamine type $2 \mathrm{C}$ receptors [47]. This interaction induces a conformational change in MUPPI and triggers a clustering of the 5 -hydroxytryptamine type $2 \mathrm{C}$ receptors at the cell membrane, triggering downstream signal transduction pathways. It is of interest that different PDZ domains of MUPPl can bind to CADMl, a transmembrane cell adhesion protein, with different affinities. The PDZ2 of MUPP1, for example, presents the highest affinity for CADMl, but when this PDZ is absent, CADMl can still interact with other PDZ domains of MUPPl. These data could point to a change in conformation of MUPPI that would unmask the PDZ2 domain leading to a strong binding to CADM1 $[48,49]$. In the case of CADMl and maybe of other interactors of MUPP1, the interactions with multiple domains can be an alternative when some domains are either occupied by other ligands or hidden by an autoinhibitory conformation of MUPP1. These multi-low-affinity interactions might then serve as transient interaction contacts before MUPPI reaches its stretched configuration. However, the unfolding/folding regulation of MUPP1 is still under debate as only indirect evidence has been obtained to date.

PAR3 is part of the Partitioning defective proteins and presents a CRI oligomerization domain, 3 PDZ domains and aPKC binding domain. A recent study pointed out that cortical forces are responsible for the clustering of PAR3 on the cell cortex. In C. elegans, inhibition of actin contraction with blebbistatin or actin filament 
polymerization causes a reduction of the PAR3 clusters on the 204 cortex, demonstrating that higher cortical tension can drive 205 PAR3 cluster formation at the cortex [50]. The actomyosin mem- 206 brane associated network generates flows [51], which promote 207 symmetry breaking along the anterior posterior axis through the 208 advection of polarity components [52-54]. The polarized actomy- 209 osin contractions pull actin networks along the membrane toward 210 the anterior region while triggering local disassembly and turnover 211 via increased local tension, resulting in flow of material [55]. Based 212 on the advective flow model proposed by Goerhing et al. [53] that 213 predicts that diffusivity and turnover of cortical polarity proteins 214 should be slow and stable enough to be passively transport by the 215 advective cortical flow, Wang et al. [50] postulate a "clustering and 216 stabilization" hypothesis for PAR3. By using fluorescence recovery 217 after photobleaching, they demonstrate that the half-life of PAR3 218 and PKC are shorter before symmetry breaking. During the early to 219 middle establishment phase, when the clusters are formed, the half- 220 life increases. Molecularly, during this phase the activity of Cdc42 is 221 reduced allowing PKC3 and PAR6 to associate with PAR3 clusters 222 at the cortex and thus facilitates effective transport by advective 223 cortical flows. During the maintenance phase, the half-lives of 224 PAR3 and PKC are shorter, when the clusters disassemble, con- 225 comitant with an increased activity of Cdc42 that prevents PKC and 226 PAR6 association with PAR3. As cortical tensions trigger a dynamic 227 equilibrium between an unclustered and clustered form of PAR3 228 correlating with its association with PAR6 and PKC, it is tempting 229 to speculate that PAR3 may undergo structural changes by 230 mechanical stretching, which could relieve the amino-terminal 231 CRl domain from intramolecular inhibitions, thus promoting 232 PAR3 oligomerization [56]. These mechanically induced confor- 233 mational changes may directly activate the ability of the CRl 234 domain to facilitate its oligomerization, and proper localization in 235 cells [56]. Furthermore, similar cortical flows are observed during 236 cell division or cell migration, and then could, if proven, also 237 explain the interaction between the different members of the PAR 238 complex.

In this part, we will describe how some PDZ proteins interact with 242 proteins that are activated upon forces. These interactions may 243 trigger a change in the conformation or in the localization of the 244 "second line" mechanotransducers, thereby regulating different 245 signal pathways. 
PAR6 is part of the Partitioning defective proteins in C. elegans, and encodes a protein with PKC binding domain (PBI), a semiCdc42/Racl interactive binding (CRIB) and a PDZ domain [57]. Recently a PDZ binding motif (PBM) was identified at its $\mathrm{C}$-terminal region [58]. PAR6 in many species is involved in cell division, cell polarization, and cell migration, processes that are characterized by changes in cellular forces [59-61].

PAR6 function is able to segregate to the apical or leading edge of epithelial cells upon activation by Cdc42-GTP [57, 62]. Accumulating evidence indicates that $\mathrm{Cdc} 42$ responds to and is activated upon different mechanical loads such as hyperosmolarity, shear stress, and intercellular increased tension [63]. Upon exposure to mechanical loads, Cdc42 translocates from cytosol to the membrane and is concomitantly activated [64]. Activation of Cdc42 by exchange of GDP for GTP triggers actin polymerization and generation of tension $[65,66]$. Binding of activated Cdc42G] CRIB domain of PAR6 favors the interaction with CRUNivu over the interaction with PALSI through a change in conformation of the CRIB-PDZ domains of PAR6 [67]. Upon Cdc42-GTP binding, a portion of the flexible CRIB motif folds into a stable conformation with the PDZ domain [68], triggering an increase affinity for the interaction with CRUMBS, and releasing the interaction with PALS1. The modular nature of PAR6 may allow the mutually exclusive interaction of CRUMBS and PALS1 with its PDZ domains, regulating the assembly and localization of different polarity complexes depending on the cellular context.

The localization of PAR6 to the plasma membrane depends on both the PDZ and the PBM domains, as both deletions caused a strong mislocalization of PAR6 to the cytosol. The PBM domain binds with different affinities to the PDZ1 and PDZ3 of PAR3, whose clustering is mediated by an increase in cortical tension as previously mentioned [50]. The weak but multivalent interaction of one PAR3 molecule with two PAR6 molecules might allow the assembly a large cluster of PAR complexes at the cell membrane. The formation of the large-scale cluster of PAR complexes can facilitate the actomyosin dependent advective transport of several PAR6 proteins during the establishment of polarity but also the formation of large clusters made with several proteins such as aPKC, PALS1, or CRUMBS that can serve different functions. domain. DLG is a member of the basolateral polarity complex SCRIBBLE, and is involved in processes such as cell division, cell migration and cell polarity [69] The N-terminal L27 domain interacts with the two L27 domains of calcium/calmodulin-dependent serine protein kinase (CASK) [70]. CASK is a membrane-associated 
demonstrated to recruit or organize other proteins at the plasma 295 membrane to coordinate signal transduction pathways within the 296 cytoplasm and nucleus [71]. A study done in 2016, using a cell 297 mechanical stretch device shows that CASK expression and locali- 298 zation to the basal membrane is needed for the inhibition of 299 proliferation of cells under cyclic stretch [72]. The authors show 300 that CASK interacts with $ß 1$-integrin, however, the tension-driven 301 interaction between these two proteins still has to be formally 302 proven. Depletion of CASK results in aberrant proliferation of 303 cells under mechanical stress demonstrating that CASK localization 304 under tension is important for the mechanoregulation of the cell 305 division [72]. In 2019, Porter et al. demonstrated that the direct 306 interaction of CASK with DLG is required for normal cortical 307 recruitment of NUMA, a key component of spindle orientation 308 machinery [73]. Disruption of this interaction affects the integrity 309 of epithelial architecture and results in misoriented cell division that 310 give rise to multilumen cyst in 3D. Since the formation of 3D cysts 311 generates an increase in tension at the cell-cell interface [74], it is 312 tempting to speculate that CASK is recruited at the cell-cell inter- 313 face in a force-dependent manner and then will recruit DLG allow- 314 ing the formation of well polarized $3 \mathrm{D}$ cysts.

DLG interacts with the C terminal PDZ binding domain of 316 CD97 and together these proteins are part of the adherens junc- 317 tional signaling complex composed of E-cadherin and catenins 318 [75]. This macromolecular complex is linked to the F actin cortex 319 and is thus submitted to cellular forces. The localization of CD97 at 320 the plasma membrane is actin dependent as blocking actin polymer- 321 ization and elongation prevents its membrane localization. When 322 present at the cell membrane CD97 strengthens the adherens 323 junction (AJs) [76] while deletion of its PDZ binding domain 324 results in the loss of cell-cell contacts [77] upon mechanical shear 325 stress. Taken together these data show a role of CD97 in the 326 mechanoregulation of cell-cell contacts. In a recent study, mechan- 327 ical stimulation of epithelial cells applied by using shear stress or 328 wound assay results in a rapid phosphorylation of Ser740 of CD97. 329 This phosphorylation disrupts the binding of DLGl to the PDZ 330 binding domain of CD97, and correlates with a disorganization of 331 the actin cytoskeleton. PKC contributes to the mechanical force 332 induced cellular responses [78] and is a potential candidate to 333 phosphorylate CD97 at S740. PKC $\alpha$ interacts via its PBM with 334 PDZ3 domain of DLGl [79]. Upon mechanical stress, PKC $\alpha 335$ might be recruited to the cell membrane via DLGl and will then 336 trigger phosphorylation of CD97 causing F-actin depolymeriza- 337 tion, loss of cell-cell contact, and DLGl detachment. This signal- 338 ing pathway when activated induces depolymerization of actin and 339 loss of cell-cell contacts, that will result in a relaxation of the 340 tension at this particular cellular junction avoiding tissue breaking. 341 
4.3 Afadin
Afadin is a filamentous actin binding protein with two Ras domains, a forkhead association domain, a dilute domain, a PDZ domain, and three proline-rich domains. Afadin is implicated in many cellular processes from cell survival, cell proliferation to cell migration and formation of the apical junctions in epithelial cells [80-83]. Afadin can interact both directly or indirectly with the actin cytoskeleton through several partners such as JAM-A, $\mathrm{ZO1} / \mathrm{ZO} 2$, vinculin, and $\alpha$-actinin [84-88]. Afadin is thus a strong candidate to be involved in mechanoregulated processes as many of its partners have been already linked to mechanotransduction. Interestingly, depletion of Afadin, JAM-A or double depletion of $\mathrm{ZOl} / \mathrm{ZO} 2$ results in similar phenotypes with increased contractility triggered by activation of RhoA and phosphorylation of myosin-light chain [89-91]. In response to $\mathrm{ZO1} / \mathrm{ZO} 2$ double depletion, Afadin is recruited to the cellular cell contacts, and inhibiting contractility perturbs the homogeneous localization of Afadin. Thus, myosin contractility is essential for maintaining Afadin uniform distribution along the zonula adherens (ZA). Removing Afadin in $\mathrm{ZOl} / \mathrm{ZO} 2$ depleted cells specifically altered actomyosin architecture at the ZA of tricellular junctions where actin cables are anchored. This perturbation is accompanied by discontinuities in the E-cadherin, claudin, and occludin stainings [92]. Taken together, this data shows a synergy between ZO and Afadin depletions in disrupting tissue integrity under tension. Afadin may therefore act as a robust protein scaffold that maintains ZA architecture at tricellular junctions.

JAM-A, a component of the TJs, via its PDZ binding motif, can associate with signaling molecules such as scaffold PDZ proteins, $\mathrm{ZOl} / 2$, and Afadin, as well as with the guanine exchange factor PDZ-GEF2 [83, 93]. Monteiro et al. demonstrate that JAM-A interacts with Afadin, ZO2, and PDZ-GEFl to activate the small GTPase Rap2c [89]. The activation of Rap2c controls the contraction of the apical cytoskeleton regulating the epithelial permeability to prevent cell injury. In this study, the authors also mention that Afadin is able to immunoprecipitate a doublet of JAM-A that might represent phosphorylated forms of JAM-A, although they did not investigate this phosphorylation but another team did. Scott at al show that mechanical stimulation can trigger phosphorylation of JAM-A [94]. Forces were applied by using fluid shear stress or by using magnetic tweezer. After applying forces, several biochemical analyses were performed that demonstrate that tension induces rapid phosphorylation of JAM-A S284. This phosphorylation of JAM-A induces activation of RhoA by PKC $\zeta$ triggering cell stiffening by modifying actin cytoskeleton. These results clearly demonstrate that JAM-A is a direct transducer of mechanical forces. Interestingly, when JAM-A is localized at the TJs which are under high levels of tension [95] it is phosphorylated [96]. It is thus tempting to speculate that mechanical tension, above a certain 
threshold might induce the phosphorylation of JAM-A. This phos- 391 phorylation will control the affinity for Afadin thereby controlling 392 the contraction of apical cytoskeleton that allows for the mainte- 393 nance of ZA and TJs.

SCRIBBLE is a classical multimodular scaffold protein that con- 396 tains 16 leucine-rich repeats (LRR) and four PDZ domains. 397 $\mathrm{N}$-terminal LRR domain can associate with LGL and is required 398 for the association with the lateral cortex and the establishment of 399 apicobasal polarity $[97,98]$. The C-terminal PDZ domains of 400 SCRIBBLE can interact with a diverse range of proteins such as 401 $\beta$-Pix [99], Vangl2 [100], and LGN [101], allowing for cell polari- 402 zation, cell migration [102], establishment of planar cell polarity, 403 and cell division, respectively. In epithelial cells, SCRIBBLE is 404 required for normal intercellular adhesion by stabilizing E-cad- 405 herin-pl20 catenin at the plasma membrane [103]. 10 years ago, 406 E-cadherin complex was tagged as a mechanosensor complex. Since 407 then many studies using different approaches such as FRET sensor, 408 magnetic tweezer, and cell stretching have confirmed that 409 E-cadherin can sense changes in mechanical forces within an epi- 410 thelial monolayer [104-106]. The role of SCRIBBLE in mechan- 411 otransduction has, however, not been investigated so far. Some 412 hints based on the function of SCRIBBLE in the stabilization of 413 E-cadherin point to a role in the mechanoregulation of AJs. 414 E-cadherin receptors form adhesive clusters that are coupled to 415 the contractile actomyosin cortex [107, 108]. At the cellular level, 416 E-cadherin adhesion not only binds cells together but also mechan- 417 ically couples the contractile modules of neighboring cells together 418 to generate junctional tension [109]. This junctional tension has 419 been mainly treated as homogeneous along the cell-cell interface. 420 However, E-cadherin forms clusters of different sizes along the 421 junctions between cells [108-110]. Interestingly, despite overall 422 basolateral localization, SCRIBBLE is enriched at the ZAs, where 423 it stabilizes E-cadherin-pl20 catenin adhesions [111, 112]. At the 424 level of the ZAs, clusters of stabilized E-cadherin are linked to large 425 actomyosin bundles [113-115]. Below the AJs, at the lateral adhe- 426 rens junctions (LAJs), E-cadherin is coupled to less aligned acto- 427 myosin network. Contractile tension is thereby greater at the ZA 428 than at the LAJ. SCRIBBLE could be enriched at the ZA in a 429 tension-dependent manner, and thereby by stabilizing E-cadherin 430 could be implicated in a feedback positive loop in the generation of 431 forces at the ZAs. This tension driven localization of SCRIBBLE to 432 E-cadherin can also take place during the orientation of the mitotic 433 spindle to align epithelial cell division. In 2017, Hart et al., by 434 applying uniaxial stretch on epithelial cells, showed that cell division 435 aligned with the stretch axis [116]. The orientation of this cell 436 division axis requires trans-engagement of E-cadherin adhesions 437 and involves tension-dependent recruitment of LGN to 438 
E-cadherin. LGN can directly interact with the cytosolic tail of E-cadherin that localizes LGN at the cell-cell contacts [117]. Increase in tension does not trigger a polarized distribution of E-cadherin, while LGN and myosin IIA are polarized suggesting that an additional intermediate, LGN interacting protein might be involved in its polarized localization. This protein could be SCRIBBLE as other ones (DLG, Afadin, ERM proteins) were ruled out in this study. SCRIBBLE is indeed able to interact with LGN, and the interaction between LGN and E-cadherin is reduced in cells depleted for SCRIBBLE. The formation of this ternary complex is also important for proper cell division [101]. Taken together, all these data point to SCRIBBLE as a likely "second line" mechanotransducer to trigger signaling pathways downstream of the mechanosensitive E-cadherin units.

439

440 441

In the last two decades, mechanical stimuli have emerged as essential regulators of several biological processes. Mechanotransduction has revealed a new layer of control of the interaction between proteins, and will potentially lead to global guiding principles for the organization of complex living systems. The convergent interests from physicists and biologists to understand the complexity of integrated systems have led to the development of new biophysical tools. These new technological advances such as stretching devices, optical/magnetic tweezers, or atomic force microscopy have enabled to measure and apply controlled forces on cells. Applying different forces on cells trigger several cellular responses and activate different signaling pathways that have led to the identification of an emerging mechanotransducing function for PDZ proteins. These mechanotransducers can participate in mechanoreception and mechanotransmission as direct mechanosensitive components or as second line mechanotransducers.

Pulling forces generated by the actomyosin network can stretch molecules exposing their cryptic binding sites or cryptic phosphorylation sites, triggering specific signaling pathways $[5,118]$. In the case of $\mathrm{ZOl}$, physical forces are responsible for the stretching of the molecule that is needed for its correct localization while allowing for the interaction with its different partners. This activated unfolded $\mathrm{ZOl}$ protein is important for the maintenance of the TJs. The actomyosin network can thus directly by its contractions pull on proteins but also on the actin cytoskeleton, resulting in flow of material that leads to the formation of polarized clusters of proteins at the cell cortex that allow for adaptation of cell cytoskeleton $[51,119]$. Under higher cortical tension PAR3 clusters and MUPPI is recruited to the cell cortex. The tension-dependent clustering of PAR3 could promote its oligomerization at the cell
455 
cortex where it could recruit PAR6 and aPKC, leading to the 485 establishment of anteroposterior or apicobasal polarity. The recruit- 486 ment of the PDZ protein MUPPl to the TJs is key to maintaining 487 the integrity of the TJ barrier during hyperosmotic stress. Finally, 488 loading forces can regulate cell adhesion machineries [105, 106, 489 120]. The adhesive contacts can adapt to external forces, by mod- 490 ifying their binding to specific proteins, their structural conforma- 491 tions, their stability but also their links to the actin cytoskeleton. 492 Some PDZ proteins such as SCRIBBLE, Afadin, or ZOl can, upon 493 loading forces, strengthen the cell adhesion machinery at the ZA 494 and TJs localization respectively to preserve epithelial homeostasis 495 by allowing for the proper polarization of the tissue and the tether- 496 ing of the adhesions to the actin cytoskeleton. In these cases, the 497 connections between adhesions are strengthened by assembly of 498 new components, however in other cases the connections can be 499 severed [121]. DLG is located at cell-cell contacts and upon forces 500 generation will recruit aPKC at the ZA. The recruitment of aPKC 501 by DLG at the ZA can then regulate the load of tension at the cell- 502 cell contact by controlling the depolymerization of actin and dis- 503 ruption of cell-cell contact leading to a relaxation of the tissue 504 when the forces are too elevated.

The active nature of cell adhesion machineries implies that the 506 time from the mechanosensing to the mechanoresponse is slow and 507 occurs within seconds to minutes allowing the occurrence of many 508 different interactions between proteins [122-124]. In the case of 509 PDZ scaffolds proteins, this could trigger specific interactions 510 allowing for the cells to have a multimodal adaptive "repertoire" 511 to properly adapt their responses to the change in forces.

Elsa Bazellières and André Le Bivic are supported by CNRS. This 514 project was developed in the context of the LabEx INFORM 515 (ANR-11-LABX-0054) and of the A*MIDEX project (ANR-11- 516 IDEX-0001-02) funded by the "Investissements d'Avenir" French 517 Government program.

\section{References}

1. Petridou NI, Heisenberg C (2019) Tissue rheology in embryonic organization. EMBO J 38:e102497

2. Salvi AM, DeMali KA (2018) Mechanisms linking mechanotransduction and cell metabolism. Curr Opin Cell Biol 54:114-120

3. Jaalouk DE, Lammerding J (2009) Mechanotransduction gone awry. Nat Rev Mol Cell Biol 10:63-73
4. Sidhwani P, Yelon D (2019) Fluid forces shape the embryonic heart: insights from zebrafish. Curr Top Dev Biol 132:395-416

5. Pruitt BL, Dunn AR, Weis WI, Nelson WJ (2014) Mechano-transduction: from molecules to tissues. PLoS Biol 12:e1001996

6. Dzamba BJ, DeSimone DW (2018) Extracellular matrix (ECM) and the sculpting of 
embryonic tissues. Curr Top Dev Biol 130:245-274

7. Hoffman BD, Grashoff C, Schwartz MA (2011) Dynamic molecular processes mediate cellular mechanotransduction. Nature 475:316-323

8. Depoil D, Dustin ML (2014) Force and affinity in ligand discrimination by the TCR. Trends Immunol 35:597-603

9. Chen W, Lou J, Evans EA, Zhu C (2012) Observing force-regulated conformational changes and ligand dissociation from a single integrin on cells. J Cell Biol 199:497-512

10. Hu X, Margadant FM, Yao M, Sheetz MP (2017) Molecular stretching modulates mechanosensing pathways: molecular stretching modulates mechanosensing pathways. Protein Sci 26:1337-1351

11. Pannekoek W-J, de Rooij J, Gloerich M (2019) Force transduction by cadherin adhesions in morphogenesis. F1000Res 8:1044

12. Cailliez F, Lavery R (2005) Cadherin mechanics and complexation: the importance of calcium binding. Biophys J 89:3895-3903

13. Springer TA, Dustin ML (2012) Integrin inside-out signaling and the immunological synapse. Curr Opin Cell Biol 24:107-115

14. Rutherford SL, Zuker CS (1994) Protein folding and the regulation of signaling pathways. Cell 79:1129-1132

15. Papagrigoriou E, Gingras AR, Barsukov IL, Bate N, Fillingham IJ, Patel B, Frank R, Ziegler WH, Roberts GC, Critchley DR, Emsley J (2004) Activation of a vinculin-binding site in the talin rod involves rearrangement of a fivehelix bundle. EMBO J 23:2942-2951

16. Smith ML, Gourdon D, Little WC, Kubow KE, Eguiluz RA, Luna-Morris S, Vogel V (2007) Force-induced unfolding of fibronectin in the extracellular matrix of living cells. PLoS Biol 5:e268

17. Manjunath GP, Ramanujam PL, Galande S (2018) Structure function relations in PDZdomain-containing proteins: implications for protein networks in cellular signalling. J Biosci 43:155-171

18. Lee H-J, Zheng JJ (2010) PDZ domains and their binding partners: structure, specificity, and modification. Cell Commun Signal 8:8

19. Charras G, Yap AS (2018) Tensile forces and mechanotransduction at cell-cell junctions. Curr Biol 28:R445-R457

20. Heinemann U, Schuetz A (2019) Structural features of tight-junction proteins. Int J Mol Sci 20:6020
21. Stevenson BR, Siliciano JD, Mooseker MS, Goodenough DA (1986) Identification of ZO-1: a high molecular weight polypeptide associated with the tight junction (zonula occludens) in a variety of epithelia. J Cell Biol 103:755-766

22. Fanning AS, Jameson BJ, Jesaitis LA, Anderson JM (1998) The tight junction protein ZO-1 establishes a link between the transmembrane protein occludin and the actin cytoskeleton. J Biol Chem 273:29745-29753

23. Itoh M, Nagafuchi A, Moroi S, Tsukita S (1997) Involvement of ZO-1 in cadherinbased cell adhesion through its direct binding to $\alpha$ catenin and actin filaments. J Cell Biol 138:181-192

24. Itoh M, Furuse M, Morita K, Kubota K, Saitou M, Tsukita S (1999) Direct binding of three tight junction-associated Maguks, Zo-1, Zo-2, and Zo-3, with the Cooh termini of claudins. J Cell Biol 147:1351-1363

25. Wittchen ES, Haskins J, Stevenson BR (1999) Protein interactions at the tight junction. Actin has multiple binding partners, and ZO-1 forms independent complexes with ZO-2 and ZO-3. J Biol Chem 274:35179-35185

26. Remue E, Meerschaert K, Oka T, Boucherie C, Vandekerckhove J, Sudol M, Gettemans J (2010) TAZ interacts with zonula occludens- 1 and -2 proteins in a PDZ-1 dependent manner. FEBS Lett 584:4175-4180

27. Balda MS, Matter K (2000) The tight junction protein ZO-1 and an interacting transcription factor regulate ErbB-2 expression. EMBO J 19:2024-2033

28. Spadaro D, Tapia R, Jond L, Sudol M, Fanning AS, Citi S (2014) ZO proteins redundantly regulate the transcription factor DbpA/ZONAB. J Biol Chem 289:22500-22511

29. Balda MS, Garrett MD, Matter K (2003) The ZO-1-associated Y-box factor ZONAB regulates epithelial cell proliferation and cell density. J Cell Biol 160:423-432

30. Sourisseau T, Georgiadis A, Tsapara A, Ali RR, Pestell R, Matter K, Balda MS (2006) Regulation of PCNA and cyclin Dl expression and epithelial morphogenesis by the ZO-1-regulated transcription factor ZONAB/DbpA. Mol Cell Biol 26:2387-2398

31. Spadaro D, Le S, Laroche T, Mean I, Jond L, Yan J, Citi S (2017) Tension-dependent stretching activates $\mathrm{ZO}-1$ to control the 
junctional localization of its interactors. Curr Biol 27:3783-3795.e8

32. Then C, Bergler T, Jeblick R, Jung B, Banas B, Krämer BK (2011) Hypertonic stress promotes the upregulation and phosphorylation of zonula occludens 1. Nephron Physiol 119:p11-p21

33. Fanning AS, Ma TY, Anderson JM (2002) Isolation and functional characterization of the actin binding region in the tight junction protein ZO-1. FASEB J 16:1835-1837

34. Fanning AS, Little BP, Rahner C, Utepbergenov D, Walther Z, Anderson JM (2007) The unique-5 and -6 motifs of ZO- 1 regulate tight junction strand localization and scaffolding properties. Mol Biol Cell 18:721-731

35. Umeda K, Ikenouchi J, Katahira-Tayama S, Furuse K, Sasaki H, Nakayama M, Matsui T, Tsukita S, Furuse M, Tsukita S (2006) ZO-1 and ZO-2 independently determine where claudins are polymerized in tight-junction strand formation. Cell 126:741-754

36. Ikenouchi J, Umeda K, Tsukita S, Furuse M, Tsukita S (2007) Requirement of ZO-1 for the formation of belt-like adherens junctions during epithelial cell polarization. J Cell Biol 176:779-786

37. Rodgers LS, Beam MT, Anderson JM, Fanning AS (2013) Epithelial barrier assembly requires coordinated activity of multiple domains of the tight junction protein $\mathrm{ZO}-1$. J Cell Sci 126:1565-1575

38. Odenwald MA, Choi W, Buckley A, Shashikanth N, Joseph NE, Wang Y, Warren MH, Buschmann MM, Pavlyuk R, Hildebrand J, Margolis B, Fanning AS, Turner JR (2017) ZO-1 interactions with F-actin and occludin direct epithelial polarization and single lumen specification in 3D culture. J Cell Sci 130:243-259

39. Fanning AS, Anderson JM (2009) Zonula occludens- 1 and -2 are cytosolic scaffolds that regulate the assembly of cellular junctions. Ann N Y Acad Sci 1165:113-120

40. Ullmer C, Schmuck K, Figge A, Lübbert H (1998) Cloning and characterization of MUPPl, a novel PDZ domain protein. FEBS Lett 424:63-68

41. Assémat E, Bazellières E, Pallesi-Pocachard E, Le Bivic A, Massey-Harroche D (2008) Polarity complex proteins. Biochim Biophys Acta 1778:614-630

42. Lanaspa M, Andres-Hernando A, Rivard C, Dai Y, Berl T (2008) Hypertonic stress increases claudin-4 expression and tight junction integrity in association with MUPPI in
IMCD3 cells. Proc Natl Acad Sci U S A 105:15797-15802

43. Latorre IJ, Roh MH, Frese KK, Weiss RS, Margolis B, Javier RT (2005) Viral oncoprotein-induced mislocalization of select PDZ proteins disrupts tight junctions and causes polarity defects in epithelial cells. J Cell Sci 118:4283-4293

44. Shin K, Straight S, Margolis B (2005) PATJ regulates tight junction formation and polarity in mammalian epithelial cells. J Cell Biol 168:705-711

45. Straight SW, Shin K, Fogg VC, Fan S, Liu C-J, Roh M, Margolis B (2004) Loss of PALS1 expression leads to tight junction and polarity defects. Mol Biol Cell 15:1981-1990

46. Sewduth RN, Kovacic H, Jaspard-Vinassa B, Jecko V, Wavasseur T, Fritsch N, Pernot M, Jeaningros S, Roux E, Dufourcq P, Couffinhal T, Duplàa C (2017) PDZRN3 destabilizes endothelial cell-cell junctions through a $\mathrm{PKC} \zeta$-containing polarity complex to increase vascular permeability. Sci Signal 10:464

47. Bécamel C, Figge A, Poliak S, Dumuis A, Peles E, Bockaert J, Lübbert H, Ullmer C (2001) Interaction of serotonin 5 -hydroxytryptamine type $2 \mathrm{C}$ receptors with PDZ10 of the multi-PDZ domain protein MUPP1. J Biol Chem 276:12974-12982

48. Fujita E, Tanabe Y, Imhof BA, Momoi MY, Momoi T (2012) A complex of synaptic adhesion molecule CADMl, a molecule related to autism spectrum disorder, with MUPPl in the cerebellum. J Neurochem 123:886-894

49. Baliova M, Juhasova A, Jursky F (2014) Using a collection of MUPPl domains to investigate the similarities of neurotransmitter transporters C-terminal PDZ motifs. Biochem Biophys Res Commun 454:25-29

50. Wang S-C, Low TYF, Nishimura Y, Gole L, Yu W, Motegi F (2017) Cortical forces and CDC-42 control clustering of PAR proteins for Caenorhabditis elegans embryonic polarization. Nat Cell Biol 19:988-995

51. Munro E, Nance J, Priess JR (2004) Cortical flows powered by asymmetrical contraction transport PAR proteins to establish and maintain anterior-posterior polarity in the early C. elegans embryo. Dev Cell 7:413-424

52. Goehring NW, Hoege C, Grill SW, Hyman AA (2011) PAR proteins diffuse freely across the anterior-posterior boundary in polarized C. elegans embryos. J Cell Biol 193:583-594

53. Goehring NW, Trong PK, Bois JS, Chowdhury D, Nicola EM, Hyman AA, Grill SW (2011) Polarization of PAR proteins 
by advective triggering of a pattern-forming system. Science 334:1137-1141

54. Mayer M, Depken M, Bois JS, Jülicher F, Grill SW (2010) Anisotropies in cortical tension reveal the physical basis of polarizing cortical flows. Nature 467:617-621

55. McFadden WM, McCall PM, Gardel ML, Munro EM (2017) Filament turnover tunes both force generation and dissipation to control long-range flows in a model actomyosin cortex. PLoS Comput Biol 13:e1005811

56. Benton R, Johnston DS (2003) Drosophila PAR-1 and 14-3-3 inhibit Bazooka/PAR-3 to establish complementary cortical domains in polarized cells. Cell 115:691-704

57. Joberty G, Petersen C, Gao L, Macara IG (2000) The cell-polarity protein Par6 links Par3 and atypical protein kinase $\mathrm{C}$ to $\mathrm{Cdc} 42$. Nat Cell Biol 2:531-539

58. Renschler FA, Bruekner SR, Salomon PL, Mukherjee A, Kullmann L, Schütz-Stoffregen MC, Henzler C, Pawson T, Krahn MP, Wiesner $S$ (2018) Structural basis for the interaction between the cell polarity proteins Par3 and Par6. Sci Signal 11:517

59. Uroz M, Wistorf S, Serra-Picamal X, Conte V, Sales-Pardo M, Roca-Cusachs P, Guimerà R, Trepat X (2018) Regulation of cell cycle progression by cell-cell and cell-matrix forces. Nat Cell Biol 20:646-654

60. Ladoux B, Mège R-M, Trepat X (2016) Front-rear polarization by mechanical cues: from single cells to tissues. Trends Cell Biol 26:420-433

61. Trepat X, Wasserman MR, Angelini TE, Millet E, Weitz DA, Butler JP, Fredberg JJ (2009) Physical forces during collective cell migration. Nat Phys 5:426-430

62. Etienne-Manneville S, Hall A (2003) Cell polarity: Par6, aPKC and cytoskeletal crosstalk. Curr Opin Cell Biol 15:67-72

63. Lewis A, Di Ciano C, Rotstein OD, Kapus A (2002) Osmotic stress activates Rac and Cdc42 in neutrophils: role in hypertonicityinduced actin polymerization. Am J Phys Cell Phys 282:C271-C279

64. Li S, Chen BPC, Azuma N, Hu Y-L, Wu SZ, Sumpio BE, Shyy JY-J, Chien S (1999) Distinct roles for the small GTPases Cdc42 and Rho in endothelial responses to shear stress. J Clin Invest 103:1141-1150

65. Tang DD, Gunst SJ (2004) The small GTPase Cdc42 regulates actin polymerization and tension development during contractile stimulation of smooth muscle. J Biol Chem 279:51722-51728
66. Plutoni C, Bazellieres E, Le Borgne-RochetM, Comunale F, Brugues A, Séveno M, Planchon D, Thuault S, Morin N, Bodin S, Trepat X, Gauthier-Rouvière C (2016) $\mathrm{P}$-cadherin promotes collective cell migration via a $\mathrm{Cdc} 42$-mediated increase in mechanical forces. J Cell Biol 212:199-217

67. Whitney DS, Peterson FC, Kittell AW, Egner JM, Prehoda KE, Volkman BF (2016) Binding of crumbs to the Par- 6 CRIB-PDZ module is regulated by $\mathrm{Cdc} 42$. Biochemistry 55:1455-1461

68. Garrard SM, Capaldo CT, Gao L, Rosen MK, Macara IG, Tomchick DR (2003) Structure of Cdc42 in a complex with the GTPasebinding domain of the cell polarity protein, Par6. EMBO J 22:1125-1133

69. Su W-H, Mruk DD, Wong EWP, Lui W-Y, Cheng CY (2012) Polarity protein complex Scribble/Lgl/Dlg and epithelial cell barriers. Adv Exp Med Biol 763:149-170

70. Lee S, Fan S, Makarova O, Straight S, Margolis B (2002) A novel and conserved proteinprotein interaction domain of mammalian Lin-2/CASK binds and recruits SAP97 to the lateral surface of epithelia. Mol Cell Biol 22:1778-1791

71. Zhu Z-Q, Wang D, Xiang D, Yuan Y-X, Wang Y (2014) Calcium/calmodulin-dependent serine protein kinase is involved in exendin4 -induced insulin secretion in INS-1 cells. Metabolism 63:120-126

72. Jiang M, Qiu J, Zhang L, Lü D, Long M, Chen L, Luo X (2016) Changes in tension regulates proliferation and migration of fibroblasts by remodeling expression of ECM proteins. Exp Ther Med 12:1542-1550

73. Porter AP, White GRM, Mack NA, Malliri A (2019) The interaction between CASK and the tumour suppressor Dlgl regulates mitotic spindle orientation in mammalian epithelia. J Cell Sci 132:jcs230086

74. Hannezo E, Prost J, Joanny J-F (2014) Theory of epithelial sheet morphology in three dimensions. Proc Natl Acad Sci U S A 111:27-32

75. Takeichi M (2014) Dynamic contacts: rearranging adherens junctions to drive epithelial remodelling. Nat Rev Mol Cell Biol 15:397-410

76. Becker S, Wandel E, Wobus M, Schneider R, Amasheh S, Sittig D, Kerner C, Naumann R, Hamann J, Aust G (2010) Overexpression of CD97 in intestinal epithelial cells of transgenic mice attenuates colitis by strengthening adherens junctions. PLoS One 5:e8507 
77. Hilbig D, Sittig D, Hoffmann F, Rothemund S, Warmt E, Quaas M, Stürmer J, Seiler L, Liebscher I, Hoang NA, Käs JA, Banks L, Aust G (2018) Mechanodependent phosphorylation of the PDZ-binding Motif of CD97/ADGRE5 modulates cellular detachment. Cell Rep 24:1986-1995

78. Sivaramakrishnan S, Schneider JL, Sitikov A, Goldman RD, Ridge KM (2009) Shear stress induced reorganization of the keratin intermediate filament network requires phosphorylation by protein kinase $\mathrm{C} \zeta$. Mol Biol Cell 20:2755-2765

79. O’Neill AK, Gallegos LL, Justilien V, Garcia EL, Leitges M, Fields A, Hall RA, Newton AC (2011) PKC $\alpha$ interacts with its novel substrate discs large homolog (DLG) 1 to promote cellular migration. J Biol Chem jbc. M111.294603

80. Kanzaki N, Ogita H, Komura H, Ozaki M, Sakamoto Y, Majima T, Ijuin T, Takenawa T, Takai Y (2008) Involvement of the nectinafadin complex in PDGF-induced cell survival. J Cell Sci 121:2008-2017

81. Sato T, Fujita N, Yamada A, Ooshio T, Okamoto R, Irie K, Takai Y (2006) Regulation of the assembly and adhesion activity of E-cadherin by nectin and afadin for the formation of adherens junctions in Madin-Darby canine kidney cells. J Biol Chem 281:5288-5299

82. Ooshio T, Kobayashi R, Ikeda W, Miyata M, Fukumoto Y, Matsuzawa N, Ogita H, Takai Y (2010) Involvement of the interaction of afadin with ZO-1 in the formation of tight junctions in Madin-Darby canine kidney cells. J Biol Chem 285:5003-5012

83. Severson EA, Lee WY, Capaldo CT, Nusrat A, Parkos CA (2009) Junctional adhesion molecule $A$ interacts with afadin and PDZ-GEF2 to activate RaplA, regulate $\beta 1$ integrin levels, and enhance cell migration. Mol Biol Cell 20:1916-1925

84. Asada M, Irie K, Morimoto K, Yamada A, Ikeda W, Takeuchi M, Takai Y (2003) ADIP, a novel afadin- and $\alpha$-actinin-binding protein localized at cell-cell adherens junctions. J Biol Chem 278:4103-4111

85. Mandai K, Nakanishi H, Satoh A, Obaishi H, Wada M, Nishioka H, Itoh M, Mizoguchi A, Aoki T, Fujimoto T, Matsuda Y, Tsukita S, Takai Y (1997) Afadin: a novel actin filament-binding protein with one PDZ domain localized at cadherin-based cell-tocell adherens junction. J Cell Biol 139:517-528
86. Mandai K, Nakanishi H, Satoh A, Takahashi K, Satoh K, Nishioka H, Mizoguchi A, Takai Y (1999) Ponsin/ SH3P12: an 1-afadin- and vinculin-binding protein localized at cell-cell and cell-matrix adherens junctions. J Cell Biol 144:1001-1018

87. Ooshio T, Irie K, Morimoto K, Fukuhara A, Imai T, Takai Y (2004) Involvement of LMO7 in the association of two cell-cell adhesion molecules, nectin and E-cadherin, through afadin and alpha-actinin in epithelial cells. J Biol Chem 279:31365-31373

88. Takai Y, Nakanishi H (2003) Nectin and afadin: novel organizers of intercellular junctions. J Cell Sci 116:17-27

89. Monteiro AC, Sumagin R, Rankin CR, Leoni G, Mina MJ, Reiter DM, Stehle T, Dermody TS, Schaefer SA, Hall RA, Nusrat A, Parkos CA (2013) JAM-A associates with ZO-2, afadin, and PDZ-GEFl to activate $\operatorname{Rap} 2 \mathrm{c}$ and regulate epithelial barrier function. Mol Biol Cell 24:2849-2860

90. Fanning AS, Van Itallie CM, Anderson JM (2012) Zonula occludens-1 and -2 regulate apical cell structure and the zonula adherens cytoskeleton in polarized epithelia. Mol Biol Cell 23:577-590

91. Miyata M, Rikitake Y, Takahashi M, Nagamatsu Y, Yamauchi Y, Ogita H, Hirata K, Takai Y (2009) Regulation by afadin of cyclical activation and inactivation of Rapl, Racl, and RhoA small G proteins at leading edges of moving NIH3T3 cells. J Biol Chem 284:24595-24609

92. Choi W, Acharya BR, Peyret G, Fardin M-A, Mège R-M, Ladoux B, Yap AS, Fanning AS, Peifer M (2016) Remodeling the zonula adherens in response to tension and the role of afadin in this response. J Cell Biol 213:243-260

93. Ebnet K, Schulz CU, Zu Brickwedde M-KM, Pendl GG, Vestweber D (2000) Junctional adhesion molecule interacts with the PDZ domain-containing proteins AF-6 and ZO-1. J Biol Chem 275:27979-27988

94. Scott DW, Tolbert CE, Burridge K (2016) Tension on JAM-A activates RhoA via GEF-Hl and pl15 RhoGEF. Mol Biol Cell 27:1420-1430

95. Priya R, Yap AS (2015) Active tension: the role of cadherin adhesion and signaling in generating junctional contractility. Curr Top Dev Biol 112:65-102

96. Iden S, Misselwitz S, Peddibhotla SSD, Tuncay H, Rehder D, Gerke V, Robenek H, Suzuki A, Ebnet K (2012) aPKC 
phosphorylates JAM-A at Ser285 to promote cell contact maturation and tight junction formation. J Cell Biol 196:623-639

97. Albertson R (2004) Scribble protein domain mapping reveals a multistep localization mechanism and domains necessary for establishing cortical polarity. J Cell Sci 117:6061-6070

98. Zeitler J, Hsu CP, Dionne H, Bilder D (2004) Domains controlling cell polarity and proliferation in the Drosophila tumor suppressor Scribble. J Cell Biol 167:1137-1146

99. Audebert S, Navarro C, Nourry C, ChasserotGolaz S, Lécine P, Bellaiche Y, Dupont J-L, Premont RT, Sempéré C, Strub J-M, Van Dorsselaer A, Vitale N, Borg J-P (2004) Mammalian Scribble forms a tight complex with the betaPIX exchange factor. Curr Biol 14:987-995

100. Kallay LM, McNickle A, Brennwald PJ, Hubbard AL, Braiterman LT (2006) Scribble associates with two polarity proteins, $\lg 12$ and vang12, via distinct molecular domains. J Cell Biochem 99:647-664

101. Wang X, Dong B, Zhang K, Ji Z, Cheng C, Zhao H, Sheng Y, Li X, Fan L, Xue W, Gao W-Q, Zhu HH (2018) E-cadherin bridges cell polarity and spindle orientation to ensure prostate epithelial integrity and prevent carcinogenesis in vivo. PLoS Genet 14:e1007609

102. Osmani N, Vitale N, Borg J-P, Etienne-Manneville S (2006) Scrib controls Cdc42 localization and activity to promote cell polarization during astrocyte migration. Curr Biol 16:2395-2405

103. Lohia M, Qin Y, Macara IG (2012) The Scribble polarity protein stabilizes E-cadherin/p120-catenin binding and blocks retrieval of E-cadherin to the golgi. PLoS One 7:e51130

104. le Duc Q, Shi Q, Blonk I, Sonnenberg A, Wang N, Leckband D, de Rooij J (2010) Vinculin potentiates E-cadherin mechanosensing and is recruited to actin-anchored sites within adherens junctions in a myosin II-dependent manner. J Cell Biol 189:1107-1115

105. Borghi N, Sorokina M, Shcherbakova OG, Weis WI, Pruitt BL, Nelson WJ, Dunn AR (2012) E-cadherin is under constitutive actomyosin-generated tension that is increased at cell-cell contacts upon externally applied stretch. Proc Natl Acad Sci U S A 109:12568-12573

106. Bazellières E, Conte V, Elosegui-Artola A, Serra-Picamal X, Bintanel-Morcillo M, RocaCusachs P, Muñoz JJ, Sales-Pardo M,
Guimerà R, Trepat X (2015) Control of cellcell forces and collective cell dynamics by the intercellular adhesome. Nat Cell Biol 17:409-420

107. Wu SK, Lagendijk AK, Hogan BM, Gomez GA, Yap AS (2015) Active contractility at E-cadherin junctions and its implications for cell extrusion in cancer. Cell Cycle 14:315-322

108. Engl W, Arasi B, Yap LL, Thiery JP, Viasnoff V (2014) Actin dynamics modulate mechanosensitive immobilization of E-cadherin at adherens junctions. Nat Cell Biol 16:584-591

109. Wu SK, Gomez GA, Michael M, Verma S, Cox HL, Lefevre JG, Parton RG, Hamilton NA, Neufeld Z, Yap AS (2014) Cortical $\mathrm{F}$-actin stabilization generates apical-lateral patterns of junctional contractility that integrate cells into epithelia. Nat Cell Biol 16:167-178

110. Lugo-Martínez V-H, Petit CS, Fouquet S, Le Beyec J, Chambaz J, Pinçon-Raymond $M$, Cardot P, Thenet S (2009) Epidermal growth factor receptor is involved in enterocyte anoikis through the dismantling of E-cadherinmediated junctions. Am J Physiol Gastrointest Liver Physiol 296:G235-G244

111. Choi J, Troyanovsky RB, Indra I, Mitchell BJ, Troyanovsky SM (2019) Scribble, Erbin, and Lano redundantly regulate epithelial polarity and apical adhesion complex. J Cell Biol 218:2277-2293

112. Yoshihara K, Ikenouchi J, Izumi Y, Akashi M, Tsukita S, Furuse M (2011) Phosphorylation state regulates the localization of Scribble at adherens junctions and its association with Ecadherin-catenin complexes. Exp Cell Res 317:413-422

113. Meng W, Mushika Y, Ichii T, Takeichi M (2008) Anchorage of microtubule minus ends to adherens junctions regulates epithelial cell-cell contacts. Cell 135:948-959

114. Priya R, Yap AS, Gomez GA (2013) E-cadherin supports steady-state Rho signaling at the epithelial zonula adherens. Differentiation 86:133-140

115. Truong Quang B-A, Mani M, Markova O, Lecuit T, Lenne P-F (2013) Principles of E-cadherin supramolecular organization in vivo. Curr Biol 23:2197-2207

116. Hart KC, Tan J, Siemers KA, Sim JY, Pruitt BL, Nelson WJ, Gloerich M (2017) E-cadherin and LGN align epithelial cell divisions with tissue tension independently of cell shape. Proc Natl Acad Sci U S A 114(29): 
E5845-E5853. https://doi.org/10.1073/ pnas. 1701703114

117. Gloerich M, Bianchini JM, Siemers KA, Cohen DJ, Nelson WJ (2017) Cell division orientation is coupled to cell-cell adhesion by the E-cadherin/LGN complex. Nat Commun $8: 1-11$

118. del Rio A, Perez-Jimenez R, Liu R, RocaCusachs P, Fernandez JM, Sheetz MP (2009) Stretching single talin rod molecules activates vinculin binding. Science 323:638-641

119. Mitrossilis D, Fouchard J, Pereira D, Postic F, Richert A, Saint-Jean M, Asnacios A (2010) Real-time single-cell response to stiffness. PNAS 107:16518-16523

120. Choquet D, Felsenfeld DP, Sheetz MP (1997) Extracellular matrix rigidity causes strengthening of integrin-cytoskeleton linkages. Cell 88:39-48
121. Stehbens SJ, Paszek M, Pemble H, 1123 Ettinger A, Gierke S, Wittmann T (2014) 1124 CLASPs link focal-adhesion-associated 1125 microtubule capture to localized exocytosis 1126 and adhesion site turnover. Nat Cell Biol 1127 $16: 561-573$

122. Sackmann E, Smith A-S (2014) Physics of cell adhesion: some lessons from cell-mimetic systems. Soft Matter 10:1644-1659

123. Riveline D, Zamir E, Balaban NQ, Schwarz US, Ishizaki T, Narumiya S, Kam Z, Geiger B, Bershadsky AD (2001) Focal contacts as mechanosensors externally applied local mechanical force induces growth of focal contacts by an mdial-dependent and rockindependent mechanism. J Cell Biol 153:1175-1186

124. Kaverina I, Krylyshkina O, Beningo K, Anderson K, Wang Y-L, Small JV (2002) Tensile stress stimulates microtubule outgrowth in living cells. J Cell Sci 115:2283-2291
1128 